\title{
A voz que pensa: Vertentes vococêntricas do filme-ensaio
}

THE VOICE THAT THINKS: VOCOCENTRIC STRANDS OF THE ESSAY FILM

L Rafael de Almeidal

ORCID: https://orcid.org/0000-0002-7088-234X

(Universidade Estadual de Goiás, Departamento de Comunicação Social, Curso de Cinema e Audiovisual. Goiânia - GO, Brasil).

Ana Paula de Aquino Caixeta ${ }^{2}$

ORCID: https://orcid.org/0000-0001-8099-7856

(Universidade Estadual de Campinas, Departamento de Cinema, Programa de Pós-Graduação em Multimeios. Campinas - SP, Brasil).

Recebido em 11/05/2018. Aprovado em 30/04/2019.

\section{Resumo}

Avaliando a potência designada à voz em assumir o papel de materializadora da intenção reflexiva exigida pelo filme-ensaio, o presente artigo visa ponderar seus possíveis comportamentos dentro de tal domínio. Questiona-se o que aglutina os conceitos de voz metacrítica (RASCAROLI, 2009), voz heteroglóssica (LUPTON, 2011) e voz pneumática (SIEREK, 2007) fundados em torno à voz-over ensaística. Adensamonos em torno a noção de que três conceitos tão distintos de uma mesma voz denunciam seu caráter metamórfico e, desse modo, materializa o desejo de pensamento em fluxo.

Palavras-chave: Filme-ensaio. Voz. Voz-over ensaística.

\section{Abstract}

Evaluating the power assigned to the voice in assuming the role of materializing the reflexive intention required by the essay film, the present article aims to consider its possible behaviors within such a domain. It is questioned what brings together the concepts of metacritical voice (RASCAROLI, 2009), heteroglossic voice (LUPTON, 2011) and pneumatic voice (SIEREK, 2007) based around the essay voice-over. We are drawn to a notion that three concepts so distinct from the same voice denounce their metamorphic character and thus materialize the desire for flowing thought.

Keywords: Essay film. Voice. Essay voice-over. 


\section{Introdução}

Considerar o espectador e viabilizar a construção de um possível diálogo entre ele e o filme é uma das características recorrentes aos filmes-ensaio. Tal premissa leva os realizadores a elaborarem seus discursos, os quais são, muitas vezes, extremamente dotados de subjetividade, e a assumi-los como o desenvolver de uma reflexão. Como consequência disso, é comum que encontremos nos filmes ensaísticos uma voz-over subjetiva que segue apartada das imagens e pode assumir diversos tons, do sarcástico ao melancólico. Todavia, é habitual a diversas dessas obras que a voz-over soe de forma intimista e/ou convidativa, elemento cujo mérito se dá pela tão almejada aproximação ao espectador.

Avaliando a potência designada à voz em assumir o papel de materializadora dessa intenção reflexiva, o presente artigo visa ponderar acerca dos seus possíveis posicionamentos dentro do filme-ensaio. Tomando como pressuposto a importância da voz para a constituição desses filmes, questiona-se o que aglutina os conceitos de voz metacrítica (RASCAROLI, 2009), voz heteroglóssica (LUPTON, 2011) e voz pneumática (SIEREK, 2007) fundados em torno à voz-over ensaística e seus comportamentos diversos.

Acredita-se que os conceitos gerados por esses autores tendem a concordar com uma postura metamórfica assumida pela voz-over ensaística, com relação aos seus diversos comportamentos e usos práticos. Gerada a partir de uma pretensão de legitimar o processo reflexivo como um produto do pensamento. Isto é, a reflexão em seu estado mais bruto, inacabado e ainda turvo.

Metodologicamente nos amparamos em uma revisão bibliográfica focada nesses três autores, que se dedicaram a investigar as especificidades da voz no filme-ensaio, compreendendo a importância de conectar tais teorias que foram fundadas através de alicerces mais amplos, referentes aos ensaísmo fílmico e voz no cinema. O que justifica a estrutura incorporada por este artigo, que passa por uma reflexão mais geral, responsável por esclarecer as relações mais evidentes do vococentrismo nos filmes-ensaio; aprofunda nas teorias de Lupton, Rascaroli e Sierek; e direciona-se para um levantamento de características em comum e díspares dessas teorias, tentando assim estabelecer um diálogo entre três conceitos diferentes que falam de uma mesma voz. 


\section{Vertentes vococêntricas no filme-ensaio}

A introspecção de um indivíduo vem a ser, na maioria dos casos, um reflexo de suas experiências vividas cotidianamente em arenas públicas. Dessa forma, o ensaísmo fílmico apodera-se dessa projeção reflexiva do sujeito como matéria-prima e se propõe a desenvolver uma "representação abstraída e exagerada do eu em um mundo experiencial encontrado e adquirido por meio do discurso do pensar em voz alta" (CORRIGAN, 2015, p. 19). Portanto, a materialização fílmica do processo do pensar, apesar de lidar diretamente com a subjetividade, não se internaliza e relaciona apenas com o eu que se propõe a refletir. Pelo contrário, aspira pela formulação de um diálogo aberto ao público.

Em termos de linguagem cinematográfica, o "pensar em voz alta" e a postura dialógica almejada pelos filmes-ensaio se concretizam através dos artifícios da voz-over. Por definição de Stella Bruzzi (2000), a voz-over é uma banda sonora extra diegética adicionada a um filme, seja documentário ou ficção.

No geral, a voz-over fornece insights e informações que não estão disponíveis imediatamente dentro da diegese, mas, enquanto que em um filme de ficção a voz-over é tradicionalmente a de um personagem na narrativa, em um documentário, a voz-over é comum ser a de um narrador desencarnado e onisciente (BRUZZI, 2000, p. 40, tradução nossa).

Por questões históricas e estéticas próprias à constituição do documentário enquanto domínio, relaciona-se a voz-over documental à "voz de Deus" que, além das características anteriormente citadas, geralmente pertence a um eloquente narrador masculino que disserta fazendo pleno uso da retórica, a fim de explicitar e convencer o público com o seu ponto de vista. Contrariando essa perspectiva, a voz-over ensaística tem em comum com a "voz de Deus" apenas esse comportamento considerado acusmático, termo utilizado por Chion (1999) para se referir aos sons que são ouvidos, porém não vistos. No mais, a voz-over utilizada nos filmes-ensaios se porta de maneira bastante distinta.

Ao falar em voz acusmática, Chion (1999) se refere a uma voz desincorporada que, no entanto, habita uma zona flutuante no espaço fílmico, estando sempre sujeita a ser vista. Ainda com relação à imagem, o teórico considera que essa voz estabelece uma possível inclusão, “uma relação de poder e posse capaz de funcionar em ambas direções, a 
imagem pode conter a voz ou a voz pode conter a imagem" (1999, p. 23, tradução nossa). Isto sugere um mutualismo, contrário a total subordinação da voz em prol da imagem.

Vagando pela superfície da tela, o acousmetre gera desequilíbrio e tensão, convidando o espectador a ir ver (CHION, 1999). Essa mobilização do espectador ocorre, segundo Chion, devido a sua capacidade de: 1) estar em todos os lugares; 2) a tudo enxergar; 3) a tudo saber; e 4) a tudo fazer. Apesar de tais características parecerem remeter diretamente à "voz de Deus", o que nos soa como diferencial da voz acusmática é que sua majoritária ausência corporal não a priva de pertencer a um eu ainda-não-visto, que possui nome e o suspense de sua possível aparição. Ou seja, essa voz pertence a um sujeito reconhecível não apenas pela qualidade vocal, mas também por sua presença dentro do filme. Por mais que sua corporalidade se apresente inicialmente suspensa, enquanto espectadores temos consciência de que ele pode aparecer a qualquer instante. Nesse processo, instiga-se a imaginação do público com relação a esse personagem, de forma tal a potencialmente distanciá-lo de uma figura divina intocável, embora Chion defenda que essa voz é onipotente, onisciente e onipresente.

Pensando nas especificidades que caracterizam as vozes no cinema, podemos afirmar que a da voz do ensaio fílmico é assumida pelo sujeito enunciador criado pelo próprio autor extratextual, isto é, o realizador. Costuma ser conjugada em primeira pessoa e não se priva de adotar tons mais afetuosos, o que lhe confere um caráter confessional e vai à contramão do rigor ditatorial da "voz de Deus". Apesar disso, reconhecemos tratar-se, sobretudo, de uma voz acusmática, nos termos propostos por Chion, em que a imagem ainda-não-vista desse sujeito narrador que responde pelo realizador, pode ser revelada a qualquer instante em seus materiais fílmicos, capturados em primeira mão ou de arquivos pessoais. Seguindo apartada das imagens, essa voz "íntima, porém clara" é capaz de argumentar sem autoritarismo (WEINRICHTER, 2007, p. 29, tradução nossa), o que torna possível a construção de um discurso interlocutório capaz de envolver cineasta e espectador.

A potência da voz-over em filmes que pretendem se assumir ensaísticos é bastante latente, ao ponto de autores como Phillip Lopate assumirem como elemento primordial para a constituição e classificação dessa estética cinematográfica. Lopate (2007) formula uma espécie de "receita", que sugere em 5 passos o que é indispensável para um filmeensaio.

Segundo Lopate (2007), portanto, o filme-ensaio deve: 1) conter palavras em forma de texto; 2) esse texto deve ser bem falado; 3 ) representar uma única voz; 4) possuir 
um discurso delineado sobre um problema; 5) transmitir algo mais que informação, assumindo um ponto de vista pessoal. Em seu "ingrediente" final, o autor afirma que é fundamental que a linguagem do texto seja o mais eloquente, interessante e bem redigida possível. Ironicamente, o resultado final da receita parece ser algo com o mesmo sabor da "voz de Deus", mas em uma embalagem diferente. Isto é, em sua tentativa de valorizar a voz no filme-ensaio, o autor acaba retirando uma de suas características principais: a liberdade com relação aos rigores formais. Apesar disso, seu firme posicionamento diante da força da voz-over em detrimento da banda imagética nos serve como evidência do papel fundamental cumprido pela voz na construção de obras ensaísticas.

Motivados por essa questão, pretendemos prosseguir com o mapeamento do que tendemos a conceber como as vertentes vococêntricas do filme-ensaio. Como já adiantamos, nossa intenção é verificar o que aproxima os conceitos de voz metacrítica (RASCAROLI, 2009), voz heteroglóssica (LUPTON, 2011) e voz pneumática (SIEREK, 2007). Todos estabelecidos a partir de estudos sobre a voz-over ensaística. Sendo assim, nos propomos a adensar em autores que, menos que delimitar obrigações e prescrições para a voz, esboçam seus possíveis comportamentos.

\section{A voz metacrítica}

Laura Rascaroli (2009) avalia a má reputação da voz-over como resultado de sua rejeição pelo cinema verdade, que a considerava negativa e extremamente didática; e também pelo posicionamento desfavorável das teorias do documentário nos últimos 20 anos ao comentário verbal, que em sua maioria condenavam o uso da "voz de Deus". No entanto, a autora alega que esta crítica é pouco convincente, pois "nem todas as vozes em filmes de não-ficção podem ser equacionadas; nem todas transmitem um significado onisciente e repressivo; e elas não têm as mesmas funções no texto" (RASCAROLI, 2009, p. 64, tradução nossa). Isto é, assim como podemos encontrar uma "voz de Deus" totalmente intocável e soberana em uma narrativa documental, também podemos nos deparar com uma voz-over capaz de transitar entre o racional e emocional, pessoal e histórico, adotando uma postura maleável a favor das necessidades do discurso fílmico.

A autora busca desenvolver seu raciocínio apoiando-se em alicerces teóricos não depreciativos sobre a voz-over, elucidando características como a alteridade e desencarnação. Nesse processo, ela se aproxima da voz acusmática de Michel Chion. Ao se adensar no conceito de acousmetre, Rascaroli esclarece que seu comportamento o 
torna mais evocativo do que uma voz personificada e, ao contrário do que é previamente esperado pelos conhecidos efeitos da "voz de Deus", é capaz de preservar o senso crítico do espectador. Por tal viés, temos uma primeira característica compatível com a voz-over do filme-ensaio, que possui justamente o desejo de estabelecer diálogo com seu público, efeito possível a partir das propriedades da voz acusmática.

A partir do distanciamento proposital estabelecido pelos traços acusmáticos da voz ensaística, que narra o filme sem a obrigatoriedade de justificar sua presença através da banda imagética, Rascaroli inicia a formulação de seu conceito de voz metacrítica. De tal maneira, a autora apresenta outra forma de distanciamento extremamente necessária na construção de um filme-ensaio, a do realizador de seu material fílmico.

Na verdade, generalizando um pouco, pode-se argumentar que a voz-over do filme-ensaio, em geral, pode ser descrita como metacrítica e metahistórica. Mesmo aqueles cineastas ensaísticos que produzem suas próprias imagens, em vez de usar materiais de arquivo, de fato, ao sobrepor um comentário, distanciam-se das imagens e as examinam, quase "encontrando" e apresentando-as de novo, como objetos pré-existentes (RASCAROLI, 2009 , p. 72, tradução nossa)

Ao descrever a voz ensaística como sendo metacrítica ou metahistórica, a autora refere-se ao seu perfil analítico e reflexivo, tanto com relação às experiências do sujeito ensaístico em arena pública, quanto aos materiais fílmicos. Para que o realizador consiga tal efeito em sua narrativa, é necessário que o mesmo se desapegue dos significados e relações prévias tidos com os materiais, ainda que estes sejam de arquivos pessoais. Dessa forma, encontrará novos sentidos possíveis para aquelas imagens e/ou áudios e só assim poderá ressignificá-los a favor do discurso pretendido. O que nos remete ao movimento de "voltar a ver" proposto por Weinrichter (2007), em que essas imagens e sons são percebidos em segundo grau, com distanciamento e acuidade de quem não está sob o efeito de um primeiro contato.

Essa voz não terá nenhum compromisso de tecer comentários fidedignos ou apresentar suas clarezas; pelo contrário, ela é um instrumento livre para a construção de uma reflexão aberta e inacabada.

Um papel recorrente desempenhado pela voz-over no filme-ensaio é comentar a partir de um distanciamento crítico, analisar e interpretar os recursos visuais. Esse distanciamento crítico é, muitas vezes, paralelo ao posicionamento do cineasta, que se afasta de trás da 
câmera, de sua função criativa, tornando-se um metacrítico - das imagens, da sociedade que as produz, de seu próprio texto e de seu papel com isso. Na atividade metacrítica do ensaísta, de fato, o mundo exterior não é o único objeto de análise e avaliação. Esta atividade auto-reflexiva se estende ao ato de produção de significados fílmicos. (RASCAROLI, 2009, p. 72, tradução nossa)

Com tais características, percebemos o ensaístico dotado de uma singularidade dialética cinematográfica, na qual a obra não possui a pretensão de fechar-se em si mesma e sim de se mostrar aberta para o seu espectador. Rascaroli nos apresenta tal comportamento através da desmistificação da autoridade enunciacional proposta pela voz metacrítica. Ou seja, como elucidado anteriormente, essa voz metacrítica, caracterizada por se colocar de forma crítica e racional diante dos arquivos e materiais que mobiliza para escrever sua narrativa, nos evidencia que é um equívoco relacionar toda voz-over a um único perfil didático e ditatorial. No caso dos filmes-ensaio, temos uma voz-over altamente mutável que assume suas incertezas e inconstâncias como qualidade, não negando a possibilidade de criar informações fictícias sobre os materiais em prol da elaboração do discurso. Como resultado desse comportamento, temos a possibilidade de instigar o público, induzindo-o a estranhamentos, questionamentos e até mesmo tensões, elementos os quais engendram a abertura para o diálogo.

\section{A voz heteroglóssica}

Informal, digressivo, anti-autoritário, fragmentário, flexível e não exaustivo, são as caracterizações familiares ao ensaio citadas por Catherine Lupton (2011). Dedicandose à compreensão da voz no filme-ensaio, a autora, assim como Laura Rascaroli, também considera importante que o discurso seja construído de formas variadas, como meio de abalar a unicidade de uma voz autoritária indesejada pelo realizador ensaísta. Com tal premissa, ela formula o conceito de voz heteroglóssica:

O que me interessa nesses filmes é um estilo distinto de comentário em voz-over, que eu chamo heteroglóssica, que corrói por dentro a autoridade notória da "voz de Deus" singular e onisciente do narrador documental. Isso é possível por meio da multiplicação de narradores ou personas que fornecem o comentário, adiando ou deslocando o que eles têm a dizer em formas variadas de discurso indireto - como a carta, a citação, a recordação ou a conversa - que afirmam seu status ficcional ou, pelo menos, ontologicamente ambíguo 
em relação às pessoas reais (inclusive e especialmente ao realizador) e fomentando indeterminações, tensões e desacordos entre eles (LUPTON, 2011, p. 159-160, tradução nossa).

Lupton apresenta seu conceito já fazendo um contraponto à "voz de Deus", considerando que ao filme-ensaio se faz necessário o comportamento metamórfico desapegado de autoridade. Quando o narrador modula o tom da própria voz e tece comentários que transitam entre uma postura analítica, afetuosa, confessional ou assume o discurso indireto, falando por outro personagem, ele multiplica a si mesmo e suspende seu compromisso com a veracidade dos acontecimentos, moldando os materiais fílmicos a favor do seu discurso. Essa postura múltipla é altamente duvidosa e questionável, pois evidencia a possibilidade de manipulação por parte do realizador, tornando-se estopim de uma abertura necessária para convocar a participação mais ativa do espectador.

Dando continuidade à formulação de sua tese, Lupton novamente toma a "voz de Deus" como medida comparativa para a voz heteroglóssica ensaística.

Normalmente, a ausência da voz-de-Deus como um corpo falante visível dentro da diegese do filme, garante o seu poder sem limites - e isso é normal a ele - para fixar o conhecimento definitivo para as imagens audiovisuais. Por contraste paradoxal, a vozover heteroglóssica nunca, ou muito raramente, aparece na frente da câmera. Este efeito é frequentemente amplificado por uma divisão estratégica mais ampla entre as trilhas sonoras e imagéticas, de modo que a relação entre ambas não é casualmente e firmemente estabelecida, mas apenas sugerida através de associações; isso deixa o público com a necessidade de ativar a imaginação, ou a fé, para conectar as imagens com o que está sendo dito (mesmo quando a ligação parece óbvia) (LUPTON, 2011, p. 160, tradução nossa).

De maneira indireta a autora também coloca a voz ensaística pareada com a voz acusmática, considerando a ausência imagética da mesma. Ao assumir o comportamento de acousmetre, com a voz de um narrador ainda-não-visto, e também desprender-se da obrigatoriedade de deixar pré-estabelecidas as relações entre imagem e som, os filmesensaio conseguem articular a participação crítica do espectador e também a ativar sua capacidade de imaginação. Pois a falta de corporalidade dessa voz que comenta as imagens tambémé responsável por reforçar a dúvida, já anteriormente tensionada pela característica múltipla da voz over heteroglóssica, e ao público restam mais questionamentos referentes aos porquês da montagem. 
Reforçando a potência da voz como elemento primordial na caracterização de um filme como ensaio, Catherine Lupton afirma:

Minha hipótese é que a voz-over heteroglóssica, quando combina imagem e som através de deduções, em vez de causalidades, é um veículo especialmente privilegiado para trazer as características do ensaio para o cinema, desde que não seja exclusiva e exaustivamente utilizada. (LUPTON, 2011, p. 160, tradução nossa)

Dessa forma, apesar de considerar a importância da voz heteroglóssica para a composição do filme-ensaio, a autora propõe seu uso comedido. Tal sentença já nos indica que, se mesmo um conceito que por si só seja referente à multiplicidade de comportamento da voz-over faça indicação de seu uso parcial, logo, existem outros comportamentos dessa voz que juntos fazem um entrelaçado e caracterizam a voz-over ensaística.

\section{A voz pneumática}

Karl Sierek (2007) também se apropria do conceito de voz acusmática para estruturar um novo conceito de voz. O teórico considera a voz como uma identificação corporal muito mais precisa que a própria imagem, comentando o recorrente uso da voz acusmática nos filmes de autor: “(...) a voz se parece mais com a impressão digital, ou talvez mais ainda com a caligrafia. $\mathrm{O}$ orador dá a sua assinatura para a imagem com este sinal. Assina com a voz." (SIEREK, 2007, p. 177, tradução nossa). Dessa mesma forma, o narrador ensaístico é facilmente reconhecível dentro da narrativa e logo associamos sua "figura" a do realizador. Mesmo em casos que essa voz não é necessariamente a do diretor, temos sempre a impressão de que é ele quem assume o discurso fílmico.

Sierek avalia a potência da voz ao considerar que, ao invés de atuar com gestos imagéticos, ela lida com conceitos e, dessa forma, formula discursos. Partindo das possibilidades da voz ao lidar com os conceitos, ele então sugere a forma pneumática. Pneuma vem do grego e significa sopro, por tal pressuposto o autor conceitua:

Já antes de expressar alguma coisa, a voz "pneumática" tem essa pesada "essência", o status do Todo-Poderoso que fala do além. Ela pretende insuflar amor e vida e fornecer às imagens, sempre subjetivas, essa solidez e esse sentido unificador do qual elas se vêem privadas, especialmente quando atravessam as fronteiras da ficção (por exemplo, em filmes-ensaio). Segundo se alega, ela conceitua as imagens e finge protegê-las contra a 
sua interpretação arbitrária. Dito isto, finge e daí obtém o seu fascínio sedutor. (SIEREK, 2007, p. 177, tradução nossa).

A voz pneumática, assumindo seu aspecto de sopro ou ar, é capaz de tornar o desejo de discurso do realizador mais difuso, ameno e, dessa forma, torna-se mais sedutora. É através dessa voz que o discurso em um filme-ensaio pode, por meio da articulação da linguagem audiovisual, se passar por incerto, errante e inconcluso, por mais que ele seja fruto de uma sentença minuciosamente calculada.

No caso específico dos filmes-ensaio, mesmo caminhando totalmente apartada das imagens, a voz ensaística sugere possíveis relações com as mesmas. Como elucidado anteriormente a partir do conceito de voz acusmática de Chion, essa relação entre sonoro e imagético é de poder e posse, onde uma pode conter a outra. O que Karl Sierek propõe com a voz pneumática é que a mesma toma o poder e a posse das imagens, agregando-lhes um sentido, mas de maneira totalmente sutil, quase imperceptível. Isso se torna possível através das formas de pronúncia, da modulação do timbre.

Como vimos também no caso da voz metacrítica, de Laura Rascaroli, a voz é o instrumento fundamental para a concretização de uma postura crítica do realizador em um filme-ensaio, que abandona suas relações anteriormente tidas com o material fílmico e passa analisá-lo procurando por ressignificações úteis ao discurso pretendido. Segundo Sierek, essa materialização seria possível através do comportamento acusmático, que insere o discurso e ao mesmo tempo garante que o mesmo soe suavemente como um pensamento a ser formulado. No entanto, o autor considera que essa força da voz pneumática pode acabar sendo prejudicial, pois seu uso desregrado poderia evidenciar tal dissimulação.

Compreende-se que, ao filme-ensaio, a dose sutil de autoridade se faz necessária, como sugerido por Phillip Lopate, pois sem ela o filme corre o risco de parecer "lamentável e simplesmente patético, perdendo assim o direito de que lhe prestem atenção" (2007, p. 67, tradução nossa). Mas também a autoridade, se excessiva e explícita, tornase característica da "voz de Deus", e, quanto mais próxima dela, mais distante fica a possibilidade de se projetar dúvida e dar brechas para o espectador questionar a narrativa. Por isso, Karl Sierek não dispensa o uso da voz pneumática em filmes ensaísticos, mas aconselha o uso regrado.

Sierek conclui que, para um filme-ensaio, a forma mais esclarecedora do discurso seria um meio termo, "nem a transmigração da alma 'pneumática', nem a abstração do 
tipo panfletária, mas o conceito de uma reflexão que se torna a portadora de seus mundos visuais." (2007, p. 178, trad. nossa). Dessa forma, nos ensaios fílmicos, a mescla de vários comportamentos da voz-over ensaística é fundamental para a fundação do caráter metamórfico que é próprio da formulação do pensamento.

\section{Por uma conclusão: a voz-pensamento}

Por meio do percurso percorrido até aqui, cremos ter ficado evidente que a voz-over ensaística é percebida por seu caráter metamórfico, apresentando usos e comportamentos diversos com a intenção de materializar, por meio da verbalidade, o processo reflexivo empreendido pelo realizador-ensaísta enquanto resultado do ato de pensar. Como resultado do levantamento realizado anteriormente, nota-se que as três vertentes vococêntricas do filme-ensaio analisadas, em graus diversos e de distintas formas, fazem menção às características próprias da "voz de Deus".

Por um lado, a voz metacrítica e a voz heteroglóssica vão contra sua onisciência e autoridade enunciacional. Por outro, a voz pneumática se assume como a transmissora de um discurso, com uma pitada de autoridade velada por tons suaves e afetuosos, embora também posicione-se contra a "voz de Deus" ao discordar de sua postura singular e imutável, já indicando como sendo essencial uma mescla de comportamentos.

Todas as três teorias, de certa forma, também dialogam com a noção de voz acusmática de Chion. Por este viés, o comportamento de acousmetre, com a corporalidade suspensa e com a iminência de ser ou não revelada, garante à voz-over ensaística a possibilidade de ressignificação dos materiais fílmicos em favor do discurso pretendido.

A fluidez dos conceitos em detectar diversos comportamentos possíveis para a voz-over ensaística consolida sua característica metamórfica, seu desejo de se portar como uma voz-pensamento. "É porque, a fim de pensar, nós multiplicamos a nós mesmos, criando diálogos interiores e relações imaginárias com outros que fazem parte da nossa consciência em evolução do interior e do mundo." (LUPTON, 2011, p. 164-165, tradução nossa). Sendo assim, a voz-pensamento torna-se múltipla e altamente mutável. Com a leveza de se desprender dos rigores formais, se permite transitar entre a poética e análise, dúvida e certeza, fabulações e verdades, liberdade e autoridade, permite-se até tomar pra si a imagem e outras vozes.

Essa voz, que é própria do filme-ensaio, se pensada graficamente dentro de um filme não seria uma reta constante, mantendo-se a mesma do início ao fim, mas sim 
uma curvatura bastante oscilante com características e funções variadas. Podemos, então, pensar os conceitos anteriormente citados - voz metacrítica, voz heteroglóssica e voz pneumática - não como sendo vozes distintas e isoladas, mas sim como elementos que compõe uma única voz, a voz-pensamento. Elas se aglutinam em prol da materialização do processo de pensar dentro do filme que se pretende ensaio, agregando, ao mesmo tempo esse caráter de reflexão bruta.

\section{Referências}

BRUZZI, Stella. New Documentary: A Critical Introduction. 2000. New York: Taylor \& Francis CHION, Michel. The voice in cinema. Columbia University Press, 1999.

CORRIGAN, Timothy. O filme-ensaio: Desde Montaigne e depois de Marker. Campinas, SP: Papirus, 2015.

LOPATE, Phillip. A la búsqueda del centauro: el cine-ensayo. In: WEINRICHTER, Antonio (Org.). La forma que piensa: tentativas en torno al cine-ensayo. Pamplona: Gobierno de Navarra, 2007.

LUPTON, Catherine. Speaking Parts: Heteroglossic voice-over in the essay-film. In: KRAMER, Sven; TODE, Thomas (Org.). Der Essay film: Ästhetik und aktualität. Konstanz: UVK Verlagsgesellschaft mbH, 2011.

RASCAROLI, Laura. The personal camera: subjective cinema and thees say film. New York: Wallflower Press, 2009.

SIEREK, Karl. Voz, guía tú en el camino. El lado sonoro del ensayo fílmico. In: WEINRICHTER, Antonio (Org.). La forma que piensa: tentativas en torno al cine-ensayo. Pamplona: Gobierno de Navarra, 2007.

WEINRICHTER, Antonio. Un concepto fugitivo, notas sobre el film-ensayo. In: WEINRICHTER, Antonio (Org.). La forma que piensa: tentativas en torno al cine-ensayo. Pamplona: Gobierno de Navarra, 2007. 
${ }^{1}$ Professor do curso de Cinema e Audiovisual da Universidade Estadual de Goiás - UEG. Doutor em Multimeios pela Universidade Estadual de Campinas - Unicamp, com estágio na Universidad Complutense de Madrid. Pós-doutor pelo Programa de Pós-Graduação em Arte e Cultura Visual da Universidade Federal de Goiás - UFG. Seus interesses artísticos e científicos estão centrados hoje nos diálogos entre o cinema documentário, o filme-ensaio e o found footage. E-mail: rafaeldealmeidaborges@gmail.com

${ }^{2}$ Bacharel em Cinema e Audiovisual pela Universidade Estadual de Goiás - UEG. Mestranda em Multimeios pela Universidade Estadual de Campinas - UNICAMP. Possui interesse artístico e científico em cinema documentário e filme-ensaio, com ênfase na voz-over ensaística. E-mail: akinoanapaula@gmail. com 